\title{
O professor de geografia e a seleção de livros didáticos para o ensino fundamental
}

The teacher of geography and the selection of textbooks for elementary

\author{
school
}

\section{Hugo Gabriel Silva Mota}

\section{RESUMO}

Este texto possui dois objetivos principais no que se refere ao trabalho do professor e o processo de escolha dos livros didáticos de Geografia. O primeiro é discutir os critérios e elementos importantes quando da escolha das coleções de livros didáticos para o subsidio ao trabalho docente e, segundo, apresentar uma metodologia sistematizada de análise do livro didático que amplie os critérios e mecanismos até então utilizados para este processo. Para este trabalho foram entrevistados 25 professores de Geografia atuantes nos anos finais do ensino fundamental na cidade de Goiânia, que fazem uso frequente do livro didático durante suas aulas. Os dados revelam que os professores não possuem um método - claramente identificável - para a análise e seleção do material didático a ser utilizado, revelando, portanto, a importância de uma proposta de sistematização de critérios para orientar o professor durante o processo de escolha dos livros didáticos.

Palavras-chave: Formação continuada; Livro didático; Trabalho docente 


\section{INTRODUÇÃO}

O Trabalho do professor está associado de modo muito sensível com o uso do livro didático. Essa associação remonta a períodos antigos em que aquele que "possui o conhecimento" está sempre acompanhado de um livro (mesmo que a concepção de livro didático tenha variado bastante ao longo do tempo).

Essa relação foi objeto de inúmeras análises e trabalhos de investigação, que ora consideram o livro um instrumento importante ao trabalho do professor e ora o responsabiliza pelos problemas de não aprendizagem. No mesmo sentido, o professor que utiliza este instrumento também foi objeto de vários trabalhos de pesquisa, seja para classificá-lo como um profissional mal formado e dependente do livro didático, e, por isso, necessitado de cursos de formação e capacitação, até, mais recentemente, trabalhos que avançam na linha de considerar o livro didático um instrumento de trabalho e o professor o profissional responsável por dar a tônica e o sentido dessa relação.

Nesse sentido, considera-se que a relação professor - livro didático, começa efetivamente no processo de análise, avaliação e escolha do material didático a ser utilizado no trabalho docente, para alcançar os objetivos de ensino e aprendizagem desejados. Entende-se que o processo de escolha do livro didático é fundamental na compreensão da relação entre professor e o livro didático, pois neste momento, se expressam, dentre outros elementos, as referências teórico-metodológicas do professor, seu entendimento sobre o processo de ensino-aprendizagem e seus objetivos com o ensino de Geografia.

O processo de escolha do livro didático pode ser visto sob duas perspectivas: na primeira, um exercício regulado, burocrático e, nem sempre, de acordo com as expectativas dos professores, que o fazem apenas para cumprir determinações legais e, nesse sentido, dispensam pouco esforço e reflexão para escolher a coleção que melhor se adéque a seus objetivos. 
A segunda possibilidade, a qual este texto se assenta, considera esse processo um salto democrático para o exercício da atividade docente e o reconhecimento da capacidade do professor em selecionar o material que melhor coadune com seus objetivos, estrutura de trabalho, seus conhecimentos e principalmente com o perfil e expectativas dos educandos que se pretende ensinar.

Ainda que divirjam as opiniões a respeito desse instrumento e aos profissionais que dele se utilizem, na pesquisa que deu origem a este texto, entrevistou-se 25 professores, com a finalidade de compreender os critérios de seleção e as razões que que os fazem utilizar constantemente o livro didático para o planejamento e a condução de suas aulas. Estes professores participaram da pesquisa, por meio de um questionário on-line, respeitando os seguintes critérios: ser formado em Geografia, ser professor efetivo e atuar nos anos finais do ensino fundamental na cidade de Goiânia.

O questionário disponibilizado aos professores era composto por 35 questões dispostas entre perguntas abertas (15) e fechadas (20) dividido em duas partes: na primeira o interesse foi coletar dados referentes ao perfil profissional do professor, tais como: ano de conclusão do curso e universidade de formação, tempo de carreira, carga horária, titulação profissional e a frequência da utilização do livro didático. Na segunda, o objetivo foi aprofundar especificamente sobre a utilização do livro didático e seus respectivos motivos durante as aulas de Geografia.

Investigar o processo de análise e escolha do livro didático revelou que há uma heterogeneidade de critérios, normalmente construídos de modo isolado pelos professores, sem um diálogo com outros profissionais e com pouca sistematização, tornando assim, um processo ao acaso, pensado e refletido somente no momento da escolha e, que dificilmente se materializa no cotidiano escolar como uma atividade intelectual e potencial instrumento de debate acerca do conteúdo, da avaliação, dos temas mais atuais da Geografia, etc.

Deste modo, o presente texto está organizado em quatro partes, complementares entre si, que procuram construir um panorama da relação do 
professor e o livro didático de Geografia, discutindo os elementos teóricos que permeiam essa relação e os aspectos práticos levados em consideração pelos professores durante o processo de escolha e, por fim, uma sugestão sistematizada para a análise do livro didático.

\section{A RELAÇÃO DO PROFESSOR DE GEOGRAFIA COM O LIVRO DIDÁTICO}

Atualmente há certa concordância que educando é um sujeito plural, dinâmico, inserido e influenciado socialmente e repleto de experiências de vida que o constituem como pessoa, indivíduo e cidadão e, que todas essas (e outras) questões devem ser consideradas durante sua aprendizagem. Contudo, questiona-se: porque o mesmo não se diz a respeito do professor que o ensina?

Assim, nota-se que a heterogeneidade que alcança o aluno e o faz diferenciado de todo o meio que o cerca no ambiente da sala de aula, não atinge o professor que o ensina e suas práticas. A referenciação ao professor nos parece sempre generalista, esparsa e considera todos os profissionais e suas práticas, métodos e experiências num mesmo patamar, sem fazer as necessárias distinções, especialmente no que se refere ao professor e ao livro didático.

Um exemplo de generalização do professor e de sua relação com o livro didático foi levantada por Silva (1996), ao apontar que a maior frequência na utilização deste recurso pelo professor decorre de sua fragilidade teórica e de sua elevada jornada de trabalho, o que o torna um coxo (profissional) que necessita de muletas (livro didático).

Quanto ao pensamento deste autor tecemos o seguinte questionamento: é algo inconciliável um professor com reconhecida qualificação e competência profissional fazer uso recorrente do livro didático? E mais, essa utilização sistemática é mesmo negativa para o ensino e o trabalho do professor?

Entendemos que é conciliável a utilização do livro didático com a capacidade crítica e autônoma do professor sem que haja prejuízos para o processo de ensino- 
aprendizagem da disciplina de referência, neste caso, da Geografia. E mais, que a capacitação profissional, a experiência docente e a carga horária de trabalho podem ser elementos importantes para qualificar a relação do professor com o livro didático tornando-a mais eficaz e produtiva.

Nesse sentido, não se pretende fazer uma defesa dogmática do livro didático ou do professor que o utiliza sistematicamente, por qual justificativa for, seja a de que este material preenche as lacunas de uma fragilizada formação inicial, ou ainda, por ser um dos poucos, senão único, recurso que muitos alunos dispõem de forma sistematizada para estudo em vários lugares distantes pelo país afora. Contudo, compete-nos destacar que há entre os teóricos do livro didático aqueles que defendem a utilização sistemática deste recurso, como se verifica nas palavras de Díaz (2011, p. 616),

Ao oferecer aos professores uma organização de conteúdos, um modelo didático de trabalho com esses conteúdos, atividades para os alunos desenvolverem e, em muitos casos, um manual para o professor, o livro didático se configura como um importante material na prática pedagógica, na medida em que ajuda a "clarear" parte significativa da atividade profissional diária, por exemplo, planejar as ações didático-curriculares a serem desenvolvidas nas aulas. O livro didático, muitas vezes é apresentado ao corpo docente como o único material em que são desenvolvidas, de maneira prática, as exigências de um currículo específico, que apresenta metodologia para a obtenção dos resultados esperados de aprendizagem, os conteúdos já selecionados e sequenciados (com definições, descrições e exemplos), uma série de atividades sobre eles, estratégia pedagógica que os professores deverão desenvolver na apresentação das informações, e até mesmo (por meio do manual do professor) são propostos procedimentos de avaliação da aprendizagem.

Do mesmo modo entendemos que, não convém promover uma acusação sumária ao livro didático colocando-o como o grande vilão para as mazelas da qualidade do ensino público no Brasil, creditando a ele a culpa por mascarar as deficiências do ensino e/ou da formação do professor, ou ainda, ser o responsável 
pela descaracterização da profissão docente, apresentando-se como seu substituto imediato, conforme assinala Silva (1996 p. 08),

Para boa parte dos professores brasileiros, o livro didático se apresenta como uma insubstituível muleta. Na sua falta ou ausência, não se caminha cognitivamente na medida em que não há substância para ensinar. Coxos por formação e/ou mutilados pelo ingrato dia a dia do magistério, resta a esses professores engolir e reproduzir a ideia de que sem a adoção do livro didático não há como orientar a aprendizagem.

Concordamos com o autor quando aponta que o livro didático pode apresentar problemas $^{1}$, limitações, interesses e, por vezes, incorreções conceituais ou contextuais, que devem ser vistas e enfrentadas pelos professores com autonomia e competência profissional, para identificar, debater e corrigir as eventuais falhas que este instrumento possa conter, exercendo assim, seu papel de intelectual do ensino em sua área de formação.

Sendo, portanto, parte da cultura escolar e do trabalho diário dos professores, entende-se que o manuseio, a avaliação, a crítica e a melhor utilização do livro didático devem permear as reflexões dos professores, desde o período de escolha destes materiais e, sendo mantido constantemente como ação própria do professor enquanto profissional e intelectual em sua área de conhecimento.

Contudo, para que essas ideias se efetivem no âmbito da escola, é preciso que o processo de análise e escolha do livro didático constitua-se em temas de debate dentro das universidades durante a formação inicial, para que os futuros professores sejam formados numa cultura mais qualificada de uso do livro didático, sendo capazes, por seus métodos, critérios e concepções julgar as coleções que lhe forem apresentadas e, eleger aquela que melhor dialogue com os interesses e necessidades de professores e alunos.

\footnotetext{
${ }^{1}$ É importante ressaltar que a cada processo de avaliação dos livros didáticos (PNLD), torna-se mais exigente e qualificado e, isso, tem elevado consideravelmente a qualidade dos materiais que chegam as escolas e professores deste país.
} 
No mesmo sentido, que as escolas e seus professores reconheçam esta etapa de avaliação e escolha dos livros didáticos como um importante momento da ação profissional, não sendo menor que qualquer outra atividade a ser exercida dentro da escola, demandando, portanto, tempo de reflexão, momentos de análise e debate entre os professores, com a finalidade de qualificar esta oportunidade e provocar reflexões sobre a importância do material didático para o processo de ensino aprendizagem desenvolvido em cada unidade escolar.

\section{LIVRO DIDÁTICO DE GEOGRAFIA UTILIZADO PELOS PROFESSORES PARTICIPANTES DA PESQUISA}

A partir da análise dos dados obtidos junto aos professores entrevistados, verificou-se que a principal coleção de livros didáticos adotada para o triênio 2014/2016 foi “Projeto Araribá", da Editora Moderna, representando a opção de 28\% dos pesquisados.

O interesse dos professores de Geografia no Ensino Fundamental por esta coleção, não se restringe ao contexto da cidade de Goiânia. No cenário nacional, de acordo com os dados disponibilizados no portal do FNDE (Fundo Nacional de Desenvolvimento da Educação), para o mesmo período, esta foi a principal coleção de livros didáticos adotada no país, representando $26,35 \%$ das escolhas. Esse percentual equivale a aproximadamente 3.333.109 de exemplares.

As Ainda no que se refere a escolha dos livros didáticos, constatou-se que $72 \%$ dos professores entrevistados, adotaram novas coleções para o período 2014-2016 em relação as que foram utilizadas no triênio anterior. Já $28 \%$ optaram em manter a coleção anteriormente utilizada.

Figura 11 e Erro! Fonte de referência não encontrada.2 apresentam de forma escalonada as coleções de livros didáticos escolhidas para o ensino de Geografia. Na 
primeira a opção feita pelos professores entrevistados e, a segunda, a de todos os professores de Geografia do Brasil que atuam nos anos finais do Ensino fundamental. Ainda no que se refere a escolha dos livros didáticos, constatou-se que $72 \%$ dos professores entrevistados, adotaram novas coleções para o período 2014-2016 em relação as que foram utilizadas no triênio anterior. Já $28 \%$ optaram em manter a coleção anteriormente utilizada.

Figura 1 - os livros didáticos de geografia escolhidos pelos professores participantes da pesquisa

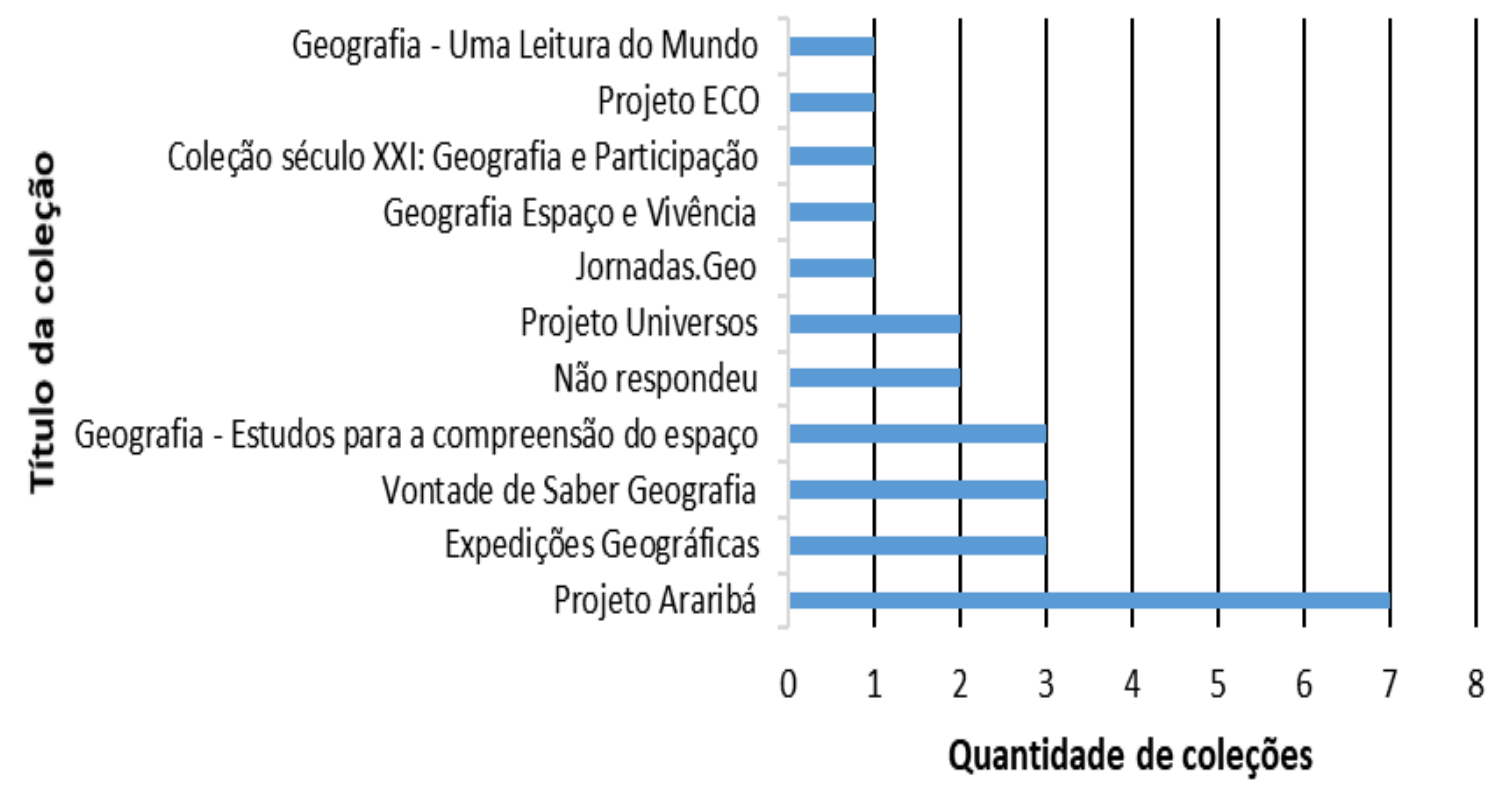

Organização: Mota, 2015 
Figura 2 - coleções de livros didáticos de geografia adquiridos no PNLD/2014

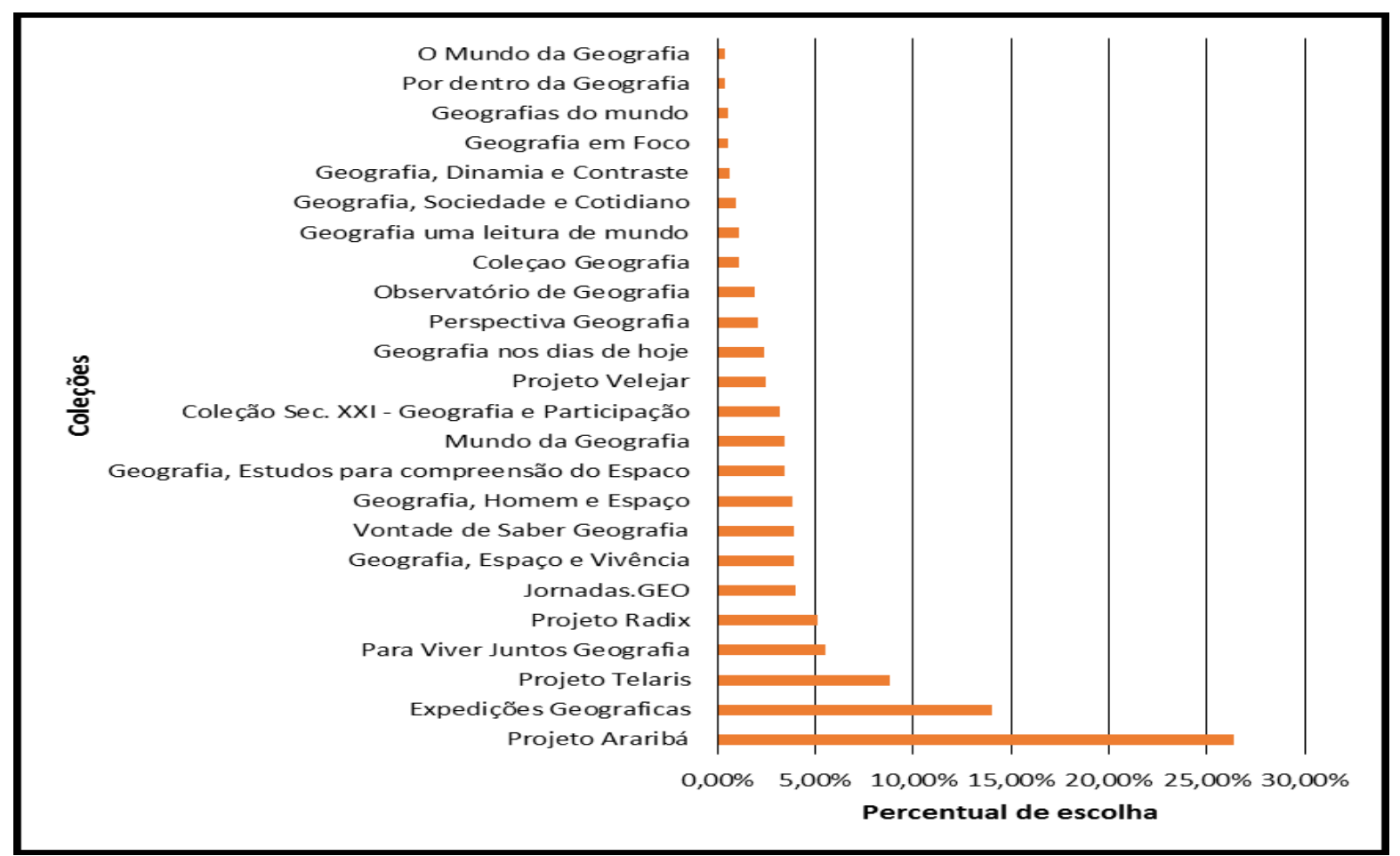

Organização: Mota, 2015

O interesse dos professores em substituir a coleção de livros didáticos, a nosso ver, indica que mesmo sendo uma questão obrigatória - a escolha de livros didáticos, os professores participantes desta pesquisa, possuem critérios e perspectivas particulares para a escolha e utilização do livro didático, que, a priori, não foram contempladas.

\section{CRITÉRIOS UTILIZADOS PELOS PROFESSORES PARA ESCOLHA DOS LIVROS DIDÁTICOS}

Dentre os principais critérios apontados pelos professores de Geografia como fundamentais para a escolha do livro didático, destacam-se a linguagem e coerência do texto (32\%), a qualidade gráfica da coleção (28\%), a qualidade e relevância das atividades (24\%) e o perfil dos educandos (16\%). 
A preocupação destes professores com a linguagem do texto presente na coleção de livros didáticos expressa a forte influência que a prática docente exerce na constituição da identidade profissional do professor e em seu trabalho docente, pois o professor ao analisar a linguagem dos conteúdos e suas abordagens, está submetendo o livro didático aos seus interesses, concepções e objetivos de ensino, assim como ao perfil e expectativas de seu alunado e, desta maneira, exercendo sua autonomia profissional.

Ao refletir e preocupar-se com a linguagem do livro didático, o professor o faz com referência ao conhecimento que possui de seus alunos, uma vez que, compete a ele diagnosticar o estágio de aprendizagem de seus educandos assim como, seus maiores interesses e as possíveis estratégias que pode vir a utilizar para alcançar seus objetivos dentro da disciplina de Geografia, por meio do livro didático.

Durante o processo de escolha do livro didático, além da valorização da linguagem, a outra característica importante para os professores durante a seleção do livro didático é a exposição gráfica dos conteúdos (28\%). Neste item a competência profissional novamente é exigida, especialmente no que se refere aos conhecimentos relativos a pedagogia e psicologia, uma vez que este critério diz respeito aos elementos cognitivos e aos estágios e modos de aprendizagem mais adequados a cada realidade e etapa do ensino.

A clareza na escolha dos livros didáticos com os quais se pretende trabalhar expressam o nível de autonomia e segurança do professor quanto a seus objetivos, expectativas e concepções de ensino, de aprendizagem e de Geografia. Isso reforça o entendimento que a utilização do livro didático pelo professor não nega ou subjuga sua capacidade e autonomia intelectual, pelo contrário, exige ainda mais desse profissional que tendo inúmeras opções de livros didáticos à disposição deve ter competência e segurança para escolher aquele que melhor se alinhe a seu trabalho como professor.

A

Figura 3 resume os principais elementos levados em consideração pelos professores de Geografia no que se refere a escolha dos livros didáticos. 
Figura 3 - principais critérios $^{2}$ utilizados pelos professores participantes da pesquisa para a escola do livro didático

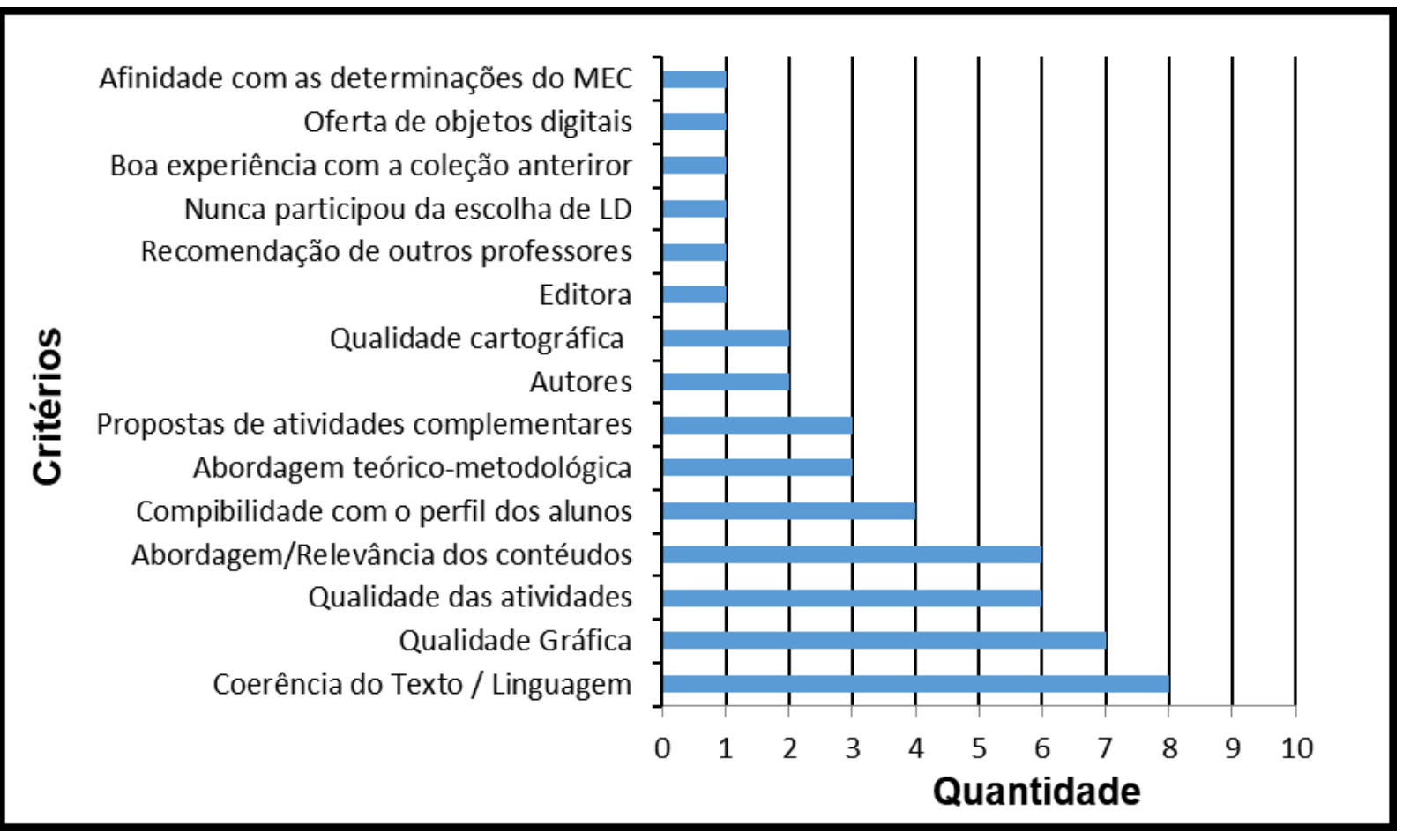

Organização: Mota, 2015

Ainda refletindo a respeito da preocupação dos professores com a expressão gráfica dos livros didáticos, aponta-se que é importante que se tenha atenção para não eleger este ou aquele material didático pela sedução mercadológica que determinadas obras possam despertar. Isso é muito comum quando o processo de escolha é feito de forma acelerada por parte dos professores que, às vezes, dispõem de um único dia para avaliar e selecionar o livro didático com o qual irão trabalhar durante três anos.

A esse respeito é importante que se reflita qual a real importância da qualidade gráfica de um livro didático para o processo de ensino-aprendizagem durante as aulas de Geografia? Ou ainda, até que ponto a qualidade estética do material didático pode contribuir para o trabalho do professor em sala de aula?

Pensamos que se deve ponderar entre a forma e o conteúdo no livro didático a ser utilizado, afim de não se optar por um material apenas por seu aspecto estético, 
desprezando a clareza conceitual, os aspectos relacionais entre os conteúdos, atividades, a possibilidade de despertar no educando a reflexão crítica, etc.

Configura-se num grave problema, a nosso ver, a adoção de livros didáticos meramente por itens estéticos e/ou por facilidades digitais, ainda que estes elementos sejam importantes durante o processo de ensino. Contudo, cabe ao professor promover uma análise mais profunda e holística da obra e do contexto em que fará uso, pois mais importante que a aparência é o aprendizado e as reflexões que o livro didático, por meio do trabalho do professor, é capaz de promover.

Outro item de grande relevância para os professores diz respeito a qualidade das atividades propostas (24\%). No Ensino Fundamental uma estratégia de ensinoaprendizagem bastante comum é a realização de atividades, normalmente situada ao final de cada capítulo ou unidade do livro didático. Essa estratégia é frequentemente utilizada por professores para melhor apreensão dos conteúdos por parte dos educandos e, para estes, representa uma ação comum para ampliarem seus conhecimentos e sistematizarem o que aprenderam.

Ao se preocupar com a qualidade das atividades, suas múltiplas possibilidades de abordagem, interpretação e reinterpretação, o professor, novamente, submete o livro didático à sua concepção de ensino e de Geografia, apontando que não são todas as atividades e/ou propostas de intervenção que lhe são adequadas ou mesmo significativas para o trabalho docente que exerce.

A autonomia para aplicar, modificar ou ignorar as atividades propostas pelos livros didáticos de Geografia é do professor, que conhece a realidade de seus alunos, suas necessidades, limitações, assim como a realidade da comunidade escolar e os objetivos da escola. Cabe ao professor coadunar esses e outros elementos durante suas aulas e utilizar de modo mais eficaz e adequado o livro didático.

A consideração do perfil dos alunos quanto a escolha do livro didático é uma preocupação de 16\% dos professores de Geografia entrevistados. Isso reforça a necessidade de o professor conhecer e identificar as necessidades, estágios de

${ }^{2}$ Neste item os professores indicaram mais de um critério para seleção dos livros didáticos. 
desenvolvimento e interesses dos seus educandos para melhor eleger o livro didático que atenda essas características. Isso, porém, exige maior tempo de atuação com os educandos, menor quantidade de escolas e salas de aula para lecionar, situações que ainda não fazem parte do cotidiano da maior parte dos professores no Brasil.

Ainda assim, os professores têm manifestado maior atenção quanto a necessidade de analisar e selecionar as atividades propostas pelo livro didático, utilizando aquelas que julgam ser mais pertinentes e coadunadas com suas expectativas de aprendizagem e critérios de avaliação. Quando as atividades propostas não se adéquam a seus objetivos os próprios professores afirmam que constroem e/ou adaptam suas atividades para a realidade da turma e seu desenvolvimento frente ao ensino de Geografia.

A respeito das atividades que utilizam para avaliarem o estágio de aprendizado dos alunos, 72\% dos professores apontaram que utilizam na mesma proporção, as atividades propostas pelo livro didático e aquelas por eles elaboradas ${ }^{3}$. O

Quadro 1 sintetiza essas informações.

Quadro 1 - as atividades utilizadas pelos professores de geografia: livro didático e autoria

\begin{tabular}{|l||c||c||}
\hline Utilização de Atividades & Professores & $\%$ \\
\hline \hline $\begin{array}{l}\text { Atividades propostas pelo livro didático e elaboradas pelo docente } \\
\text { na mesma proporção }\end{array}$ & 18 & $72 \%$ \\
\hline \hline Exclusivamente as atividades elaboradas pelo docente & 1 & $4 \%$ \\
\hline \hline Majoritariamente as atividades elaboradas pelo docente & 5 & $20 \%$ \\
\hline \hline Majoritariamente as atividades propostas pelo livro didático & 1 & $4 \%$ \\
\hline \hline Total & 25 & $100,00 \%$ \\
\hline
\end{tabular}

Organização: Mota, 2015

A partir dos critérios que os professores levam em consideração para a escolha dos livros didáticos, este texto pretende chamar a atenção para o fato que há uma

\footnotetext{
${ }^{3}$ Não foi objeto desta pesquisa analisar as atividades elaboradas pelos professores, mas as observações de campo e as conversas estabelecidas mostram que as atividades do livro didático apresentam um peso ainda maior, pois parte das atividades que são ditas "por eles elaboradas" na verdade são atividades propostas por outros livros que não os utilizados no momento.
} 
série de elementos subsumidos, ou pelo menos não sistematizados, no que se refere ao processo de análise e escolha dos livros didáticos e, que servem de ponto de partida para o estabelecimento de um processo de reflexão e formação continuada do professor de Geografia. A amplitude dos elementos qualidade das atividades e conteúdos, a adequação da linguagem e o perfil dos educandos, exige um exercício do professor para realizar de modo comparativo uma análise das diversas coleções de livros didáticos durante o período de escolha.

\section{PROPOSTA DE ANÁLISE DO LIVRO DIDÁTICO DE GEOGRAFIA A PARTIR DA PERSPECTIVA DA FORMAÇÃO CONTINUADA DO PROFESSOR}

O processo de escolha do livro didático de Geografia, mais que uma atividade pertinente ao trabalho do professor, expressa uma concepção de ensino, de aprendizagem e de profissão. Neste caso exige para além de conhecimentos relativos a disciplina de referência, o conhecimento dos alunos, do papel e importância do que se ensina, além de saberes ligados a didática, currículo, avaliação, metodologias, etc.

Procurando contribuir com o professor quando da escolha dos livros didáticos, sugere-se uma metodologia de análise do livro didático de Geografia, que valorizando os elementos já observados como importantes durante este processo, os apresentam de modo sistematizado, para que a ação seja ao mesmo tempo uma questão prática do trabalho docente, mas também, uma oportunidade de reflexão e formação continuada no efetivo exercício da profissão.

A perspectiva considerada para a formulação desta sugestão metodológica traz a tona a distinção entre os papeis de cada sujeito envolvido nessa relação, a saber, professor-aluno-livro didático. Deste modo, compete ao professor, a partir dos critérios julgados mais relevantes (conteúdos, linguagem, atividades e perfil do aluno), analisar qual a coleção melhor se ajusta a seus objetivos e interesses, assim como, ao educando, suas possibilidades e limitações. 
Ao sistematizar esses elementos numa proposta de análise de livro didático, espera-se que o professor faça suas reflexões sobre o material didático que avalia, e o submeta a seus objetivos enquanto profissional, que é capaz de analisar o conjunto da obra, seus pontos fortes e fragilidades e, assim, promover uma escolha teoricamente sustentada, que valorize seus conhecimentos profissionais e reconheça que o livro didático figura-se como um instrumento do trabalho docente, não seu guia ou direcionador.

Nesse mesmo sentido, deve-se ainda, observar o papel do educando quando do processo de análise e seleção dos livros didáticos, sua capacidade de leitura, interpretação, disposição com textos longos ou não, acesso a outras fontes de pesquisa, interesse por atividades mais ou menos reflexivas e/ou práticas, etc. Quanto melhor e mais detalhada for essa leitura dos educandos, maiores são as possibilidades de se eleger um material que desperte o interesse e favoreça o trabalho docente e o aprendizado dos mesmos durante as aulas de Geografia.

Quadro 02 2- sugestão para análise de livros didáticos para professores de geografia

\begin{tabular}{|c|c|c|c|}
\hline & PROFESSOR & ALUNO & LIVRO DIDÁTICO \\
\hline 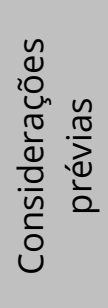 & $\begin{array}{l}\text { O que entendo por Geografia? } \\
\text { - Qual a importância dessa } \\
\text { disciplina para a educação dos } \\
\text { alunos? } \\
\text { - Quais os meus objetivos } \\
\text { dentro da disciplina para este } \\
\text { ano? }\end{array}$ & $\begin{array}{l}\text { Qual a compreensão de } \\
\text { Geografia do aluno } \\
\text { - Quais são suas } \\
\text { expectativas ou } \\
\text { resistências no que se } \\
\text { refere a essa disciplina }\end{array}$ & $\begin{array}{l}\text { Qual a concepção de Geografia } \\
\text { posta pelo livro didático? Esta } \\
\text { concepção se afina com a } \\
\text { minha visão de ensino? } \\
\text { - Conhecendo o perfil dos meus } \\
\text { educandos este livro atende as } \\
\text { necessidades e/ou expectativas }\end{array}$ \\
\hline
\end{tabular}




\begin{tabular}{|c|c|c|c|}
\hline 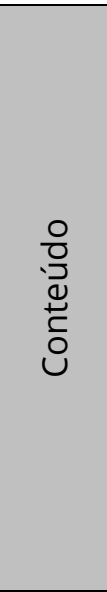 & $\begin{array}{l}\text { Quais conteúdos considero } \\
\text { fundamentais para o ensino de } \\
\text { Geografia nesta série/ano? } \\
\text { Quais os conteúdos devem ser } \\
\text { acrescentados e que devo } \\
\text { trabalhar neste ano (por força } \\
\text { de trabalhos coletivos, } \\
\text { determinação de secretarias, } \\
\text { etc.) } \\
\text { - Entre esses conteúdos quais } \\
\text { apresento maior facilidade/ } \\
\text { domínio e quais encontro } \\
\text { dificuldades? }\end{array}$ & $\begin{array}{l}\text { Esses conteúdos e sua } \\
\text { abordagem no livro } \\
\text { didático são próximas a } \\
\text { realidade dos educandos } \\
\text { ou encontro } \\
\text { possibilidades concretas } \\
\text { de aproximação a partir } \\
\text { do trabalho com o livro } \\
\text { didático? }\end{array}$ & $\begin{array}{l}\text { O livro didático contempla } \\
\text { satisfatoriamente esses } \\
\text { conteúdos que julgo essenciais } \\
\text { para o ensino de Geografia } \\
\text { Considerando os temas que } \\
\text { tenho dificuldades, o livro } \\
\text { didático os aborda de modo a } \\
\text { facilitar meu trabalho e } \\
\text { aprendizado e posterior } \\
\text { aprendizado dos educandos? } \\
\text { No Manual do professor constam } \\
\text { sugestões claras e diferenciadas } \\
\text { de como trabalhar os conteúdos? }\end{array}$ \\
\hline 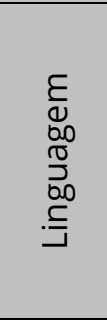 & $\begin{array}{l}\text { Qual a minha concepção de } \\
\text { linguagem aplicada ao ensino } \\
\text { de Geografia? } \\
\text { Quais as várias linguagens que } \\
\text { compreendo importantes para } \\
\text { o trabalho com os conteúdos } \\
\text { da disciplina? }\end{array}$ & $\begin{array}{l}\text { Consigo identificar as } \\
\text { várias linguagens em que } \\
\text { os educandos estão } \\
\text { inseridos? } \\
\text { Qual o nível de leitura } \\
\text { dos educandos? }\end{array}$ & $\begin{array}{l}\text { Como está materializada no livro } \\
\text { didático a exposição dos } \\
\text { conteúdos (clara, coesa, } \\
\text { fragmentária, rebuscada). } \\
\text { Quais as outras linguagens } \\
\text { presentes? Elas se ligam ao perfil } \\
\text { dos meus alunos? }\end{array}$ \\
\hline $\begin{array}{l}\frac{y}{0} \\
\frac{0}{0} \\
\frac{0}{Z} \\
\frac{D}{<}\end{array}$ & $\begin{array}{l}\text { Qual o meu conceito de } \\
\text { avaliação? Quais características } \\
\text { valorizo? Conheço as várias } \\
\text { correntes teóricas e } \\
\text { possibilidades de promover o } \\
\text { processo avaliativo do meu } \\
\text { educando? } \\
\text { Identifico os vários graus de } \\
\text { dificuldade/exigência do } \\
\text { conjunto de atividades } \\
\text { presentes no livro didático? } \\
\text { - A disposição das atividades do } \\
\text { livro didático são factíveis } \\
\text { dentro da realidade de uma } \\
\text { aula de Geografia }\end{array}$ & $\begin{array}{l}\text { Qual a relação } \\
\text { estabelecida (ou que } \\
\text { pretendo estabelecer) } \\
\text { com meus alunos a } \\
\text { respeito da avaliação? } \\
\text { Cada educando possui } \\
\text { um potencial a ser } \\
\text { avaliado, assim como } \\
\text { uma forma que melhor o } \\
\text { expresse e valorize. }\end{array}$ & $\begin{array}{l}\text { O livro didático apresenta várias } \\
\text { formas de atividades/propostas } \\
\text { avaliativas } \\
\text { - No manual do professor } \\
\text { constam sugestões para } \\
\text { aprofundamento no que se } \\
\text { refere a avaliação? } \\
\text { E possível identificar o nível de } \\
\text { aprofundamento das atividades } \\
\text { presentes no livro didático? } \\
\text { As propostas de avaliação são } \\
\text { factíveis em relação ao nível dos } \\
\text { educandos e realidade escolar } \\
\text { em que atuo? }\end{array}$ \\
\hline 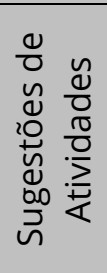 & $\begin{array}{l}\text { Compreendo a importância da } \\
\text { utilização de outras } \\
\text { metodologias e estratégias de } \\
\text { ensino aprendizagem. }\end{array}$ & $\begin{array}{l}\text { Capaz de ler no contato } \\
\text { com a turma a } \\
\text { necessidade / } \\
\text { importância de variar as } \\
\text { estratégias e } \\
\text { metodologias }\end{array}$ & $\begin{array}{l}\text { O livro didático apresenta outras } \\
\text { formas/sugestões de atividades, } \\
\text { com explicação, procedimentos } \\
\text { de execução/participação. }\end{array}$ \\
\hline
\end{tabular}

Elaboração: mota, 2015

\section{CONCLUSÃo}

Ao eleger os itens que compõem o quadro anterior como importantes durante a análise do livro didático não se tem a pretensão de restringir a capacidade de escolha do professor, que pode apresentar outros pontos de interesse e pertinência para a melhor configuração de seu trabalho docente. O que se pretende é apontar possíveis 
oportunidades de reflexão durante a prática docente, especialmente, na escolha dos livros didáticos.

Ao refletir sobre seus conhecimentos, o perfil dos educandos, a realidade em que atua e a qualidade do livro didático, em seus variados aspectos, o professor de Geografia se insere num processo de formação continuada, na qual o livro didático atua como um elemento mediador por meio dos seus conteúdos, signos, símbolos e demais elementos, potencializando o aprendizado do professor durante a ação docente.

Nesse sentido, concordamos com Kaercher (2014, p. 86), que não se trata apenas de assumir a utilização ou não do LD, mas sim, compreender que essa relação pode ser analisada e colocada em debate, sob um viés propositivo e, por assim dizer, formativo do professor.

E importante que se diga que o uso ou não do LD não e indicativo de muita coisa. Já é superada, esperamos, a fase de prejulgar os professores que o usam. Acreditamos que o LD de Geografia, em geral, são, no mínimo, úteis, já que apresentam de forma organizada uma série de informações que necessitamos.

Assim, entendemos que a utilização frequente do LD de Geografia durante as aulas, pode, também, representar coerência profissional, competência acadêmica, bem como, qualidade no trabalho desempenhado, uma vez que, parte-se do princípio que o LD é um instrumento de trabalho e nas mãos de habilidosos profissionais, os resultados tendem a ser bastante positivos.

Por fim, espera-se superar o debate acerca da fragilidade do professor frente ao livro didático ou vice-versa, mas ampliar a discussão apontando possibilidades de reflexão que considere a contribuição deste instrumento não apenas para o trabalho docente, como também, para sua formação continuada em serviço.

\section{REFERÊNCIAS}


DÍAZ. Omar Rolando Turra. A atualidade do livro didático como recurso curricular. Linhas Críticas, Brasília, DF, v. 17, n. 34 p. 609-624, set./dez. 2011.

KAERCHER, Nestor André. Se a geografia escolar é um pastel de vento o gato come a geografia crítica. Porto Alegre: Evangraf, 2014.

MOTA, Hugo Gabriel da Silva. O livro didático mediando a construção do conhecimento na formação continuada do professor de Geografia [Dissertação de Mestrado]. Instituto de Estudo Socioambientais (IESA), Universidade Federal de Goiás, Goiânia, GO. 2015, 172 f.

SILVA, Ezequiel Theodoro. Livro didático: do ritual de passagem a ultrapassagem. Em Aberto, Brasília, ano 16, n.69, jan./mar. 1996 